\title{
EFFECT OF REMINERALIZING AGENTS ON THE FLEXURAL MODULUS OF ELASTICITY OF NICKEL TITANIUM AND COPPER NICKEL TITANIUM WIRES
}

\author{
Islam Tarek Hassan *, Dina Hussien El-Ghoul** and Mohamed Khaled Fawzy ***
}

\begin{abstract}
Objective: To determine the effect of acidulated phosphate fluoride "APF" and casein phosphoprotein amorphous calcium phosphate "MI paste" on the flexural modulus of two super elastic orthodontic wires.

Material and Methods: Preformed round and rectangular NiTi and $\mathrm{Cu}$ NiTi were immersed in either APF, MI paste or artificial saliva (control) for 4 minutes. The wires were then subjected to a 3-point bend test in accordance with the American National Standard/American Dental Association Specification No. 32 (2006)
\end{abstract}

Results: NiTi wires were significantly affected by the prophylactic agents' application with a more substantial effect for those treated with APF. The effects were less in magnitude however still significant for the tested $\mathrm{Cu} \mathrm{NiTi}$ wires.

Conclusion: Mechanical properties of NiTi wires are significantly affected by the application of remineralizing agents. Clinically it would preferable to use $\mathrm{Cu}$ Niti wires if it is predicted that the patient will need a prophylactic agent.

\section{INTRODUCTION}

The orthodontic arch wire is one of the main parts of the multibracket appliance. It is designed to move teeth from malocclusion to a preferred dental occlusion through mechanical interaction with the bracket slots. Orthodontic treatment mostly constitutes of different phases with special requirements of force delivery and mechanotherapy during each phase. ${ }^{1,2}$ Generally, it is vital that wires used should generate a continuous light force within each phase of treatment ${ }^{3}$. At the same time the orthodontist's goal is to satisfactorily accomplish treatment in the least amount of time with minimum patient discomfort, while avoiding complications by maintaining healthy teeth and supporting structures. $^{4}$

Manufacturers attempt to produce wires with specific physical and mechanical properties to

\footnotetext{
* Assistant Professor of Orthodontics, Faculty of Dentistry Ain Shams University

** Lecturer of Orthodontics, Faculty of Dentistry Ain Shams University

*** Postgraduate student Orthodontics, Faculty of Dentistry Ain Shams University
} 
satisfy orthodontic requirements' yet these properties are liable to change under various manipulations and conditions ${ }^{5}$. One such condition affecting the mechanical properties of arch wires is the use of dental re-mineralizing agents which is sometimes mandatory to preserve the dental structure . $^{6}$

These agents are also used to enhance the patients' oral hygiene and as a prophylaxis to reduce the incidence of the white spot lesions commonly associated with orthodontic fixed appliances ${ }^{7,89}$. Products containing fluorides and casein phosphoprotein are the mainly prescribed prophylactic agents used for such purposes $^{7-9}$. Different protocols including professional in-office as well as home use applications are advocated throughout the orthodontic treatment period. Therefore, it is important to understand their effect on the various components of the orthodontic fixed appliances. The unique properties of superelastisty and shape memory allow titanium-based wires to deliver a constant force over a wide range of activation making them ideal for orthodontic tooth movement ${ }^{4,13}$. Accurate knowledge of the mechanical properties of these wire is essential in their utilization to deliver ideal forces for tooth movement ${ }^{14,15}$.

Titanium and titanium based alloys are known for their excellent corrosion resistance attributed to their protective oxide ${ }^{6,13}$. However previous studies have recorded discolorations, surface changes as well as changes in mechanical properties of superelastic titanium based wires in response to fluoride applications ${ }^{5,6}$. Therefore, this study was conducted to test and compare the effects of acidulated phosphate fluoride "APF" and casein phosphoprotein amorphous calcium phosphate "MI paste" on the flexural modulus of $\mathrm{NiTi}$ and $\mathrm{Cu} \mathrm{NiTi}$ wires as well as any possible influence wire cross section might have on that interaction.

\section{MATERIAL AND METHODS}

Preformed Ormco pseudo nickel titanium (NiTi) round and rectangular wires as well as thermoplastic copper nickel titanium wires ( $\mathrm{Cu} \mathrm{NiTi}$ ) were chosen for their superelastic properties and popularity.

TABLE (2) Number of wire samples distributed according to; wire alloy and wire crosssection

\begin{tabular}{|c|c|c|c|}
\hline & Material & $\begin{array}{c}\text { Cross-section in } \\
\text { Inches }\end{array}$ & $\begin{array}{c}\text { Number of } \\
\text { Wires }\end{array}$ \\
\hline Group 1 & Niti & 0.016 & 50 \\
\hline Group 2 & Niti & $17 \times 25$ & 50 \\
\hline Group 3 & Cu-Niti & 0.016 & 50 \\
\hline Group 4 & Cu-Niti & $17 \times 25$ & 50 \\
\hline
\end{tabular}

The fluoride agent used was $1.23 \% \mathrm{APF}$, Sorbet ,Dental Resources, a division of Key Stone Industry, Myerstown, Pennsylvania, USA and the casein phosphoprotein was MI Paste, GC International, Itabashi-Ku, Tokyo, Japan. (table 1)

TABLE (1) Prophylactic agents; composition and manufacturing company

\begin{tabular}{|l|l|l|}
\hline Prophylactic Agent & Composition & Manufacturer \\
\hline APF "Sorbet"TM & $\begin{array}{l}\text { Acidulated phosphate fluoride. Flouride ion 1.23\% } \\
\text { available from 2.09\% sodium fluoride and hydrofluoric } \\
\text { acid }\end{array}$ & $\begin{array}{l}\text { Dental Resources, A division of Key Stone } \\
\text { Industry, Myerstown, Pennsylvania, USA }\end{array}$ \\
\hline "MI Paste" TM & Casine phosphoprotein amorphous calcium phosphate & GC International, Itabashi-Ku, Tokyo, Japan \\
\hline
\end{tabular}


Each wire specimen was cut from the straight portion of preformed arch wires with a round crosssectional dimension of 0.016 inch and a rectangular cross- sectional dimension of $0.017 \times 0.025$ inch and were cut to the length of $20 \mathrm{~mm}$.

The wire specimens were divided into four equal groups of 50 according to the wire alloy and cross section. (Table 2)

\section{Wire treatments}

From each sub-group 10 wire specimens were allocated to be used as control samples. These wires were immersed in separate vials containing artificial saliva for 5 minutes prior to their testing. The remaining wires from each sub-group were randomly selected to be treated with either; APF or MI Paste rendering 20 wires for each treatment. The treatment consisted of a four-minute application of the prophylactic agent (total emersion of the wire in the agent in a glass bowl). After that, 10 wires of each treatment subgroup (no. of wires per sub group 20) were randomly allocated to be tested immediately after prophylactic agent application. Those wires were treated individually (one at a time) with the prophylactic agent then removed with tweezers and washed in a bowl with artificial saliva (the wires of each treatment were washed in a separate artificial saliva bowl) and tested immediately (T0). The prophylactic agent application and washing procedures were repeated for the remaining 10 wires in each subgroup allocated for delayed testing. This was followed by their storage in separate test tubes containing artificial saliva for 3 weeks. These subgroups were then tested at (T1).

\section{Testing procedure}

In our study, all specimens were subjected to a 3 -point bending test as described by Miura et $\mathrm{al}^{23}$. Mechanical testing was also based on the current American National Standard/American Dental Association Specification No. 32 for Orthodontic Wires 2006. ${ }^{5}$
As indicated in the specification, the wire specimens were submerged and tested in a heated distilled $\mathrm{H}_{2} \mathrm{O}$ bath $\left(37 \pm 1{ }^{\circ} \mathrm{C}\right)$ to simulate the aqueous oral environment. The temperature of the water bath was maintained via a water heater and a thermocouple thermometer.

The mechanical testing was performed on a computer controlled universal testing machine (Lloyd Instruments LR 5K Serial No 014441; Load cell $5 \mathrm{KN}$ ) and the data was collected using Nexygen version 4.5. The testing procedures were performed at the Dental Biomaterial Department, Faculty of Dentistry, Ain Shams University .

During the testing procedure, the wire was supported by a jig, the jig span would determine the length of the wire that was subjected to the bending test. For this test and its clinical applications, the testing procedures were customized for each wire alloy. According to a pilot testing, Titanium based alloys were tested on a $12 \mathrm{~mm}$ custom made jig span. (Figure 1).

Compressive force was applied at a crosshead speed of $1 \mathrm{~mm} / \mathrm{min}$ by means of a striker (steel rod with a bi-beveled chisel end) placed midway between the two poles of the jig. Each specimen was loaded to a deflection of $3.1 \mathrm{~mm}$ and then unloaded at the same crosshead speed until zero deflection was reached. Load in newtons $(\mathrm{N})$ and deflection in

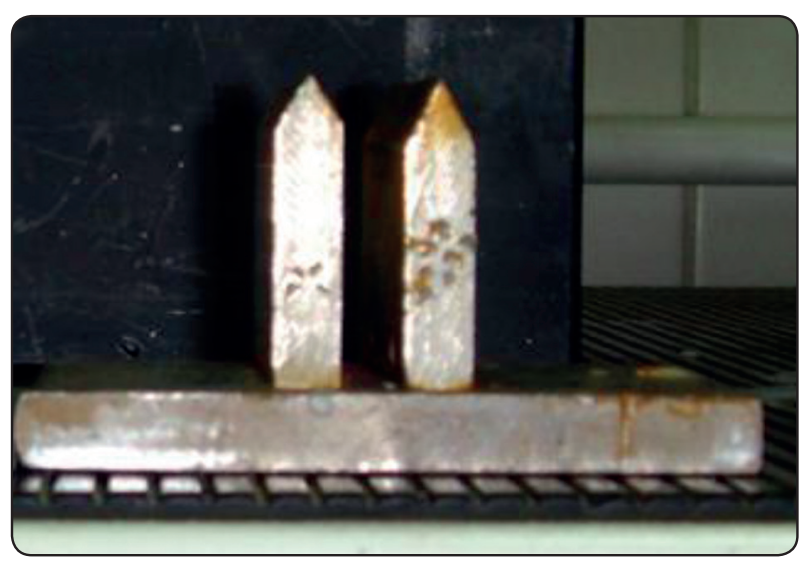

Fig. (1) Custom made testing jigs 
millimeters $(\mathrm{mm})$ were recorded for each specimen with the Nexygen computer software program. Load deflection curves were the generated via MS Excel (2010).

The engineering beam theory was used to calculate the flexural modulus of elasticity (E).E for the loading slopes of round cross section specimens was calculated using the following equation:

$\mathrm{E}=4 \mathrm{~L}^{3} \mathrm{~m} / 3 \pi \mathrm{D}^{4}(\mathrm{GPa})$.

E for the loading slopes for rectangular specimen was calculated using the following equation ${ }^{95}$ :

$$
\mathrm{E}=\mathrm{L}^{3} \mathrm{~m} / 4 \mathrm{bd}^{3}(\mathrm{GPa}) .
$$

$\mathrm{P}=$ load at the apparent yield point $(\mathrm{N}), \mathrm{L}=$ support span $(\mathrm{mm}), \mathrm{b}=$ width of specimen $(\mathrm{mm})$, $\mathrm{d}=$ depth of specimen $(\mathrm{mm})$ and $\mathrm{m}=$ slope of the straight-line portion of the loading deflection curve ( $\mathrm{N} / \mathrm{mm}$ of deflection).

\section{Statistical Method}

The Generalized Linear Model was selected because, the dependent variables are continuous
(Modulus of Elasticity E,) whilst the independent variables studied (wire dimension, prophylactic agent used and time of testing) were categorical.

The Generalized Linear Model was performed using SPSS software version 17. The analysis was performed separately for E, loading YS and unloading YS in each alloy type (NiTi and $\mathrm{Cu} \mathrm{NiTi}$ ). The Generalized linear model was used to study the effect of each of the studied independent variables (wire treatment, cross section and storage time) separately as well as their two-way interactions.

\section{RESULTS}

The results show a statistically significant decrease in the measured Modulus of Elasticity (E) the wires treated with both APF and MI Paste when compared with the control groups. In addition, the measured $\mathrm{E}$ values for the groups treated with MI Paste were significantly higher than those treated with APF. This change was less pronounced however still significant for the tested CuNiTi wires.

(Curves 1 to 6 and Table 3 to 7 )

\section{A representative sample of the generated load deflection curves}

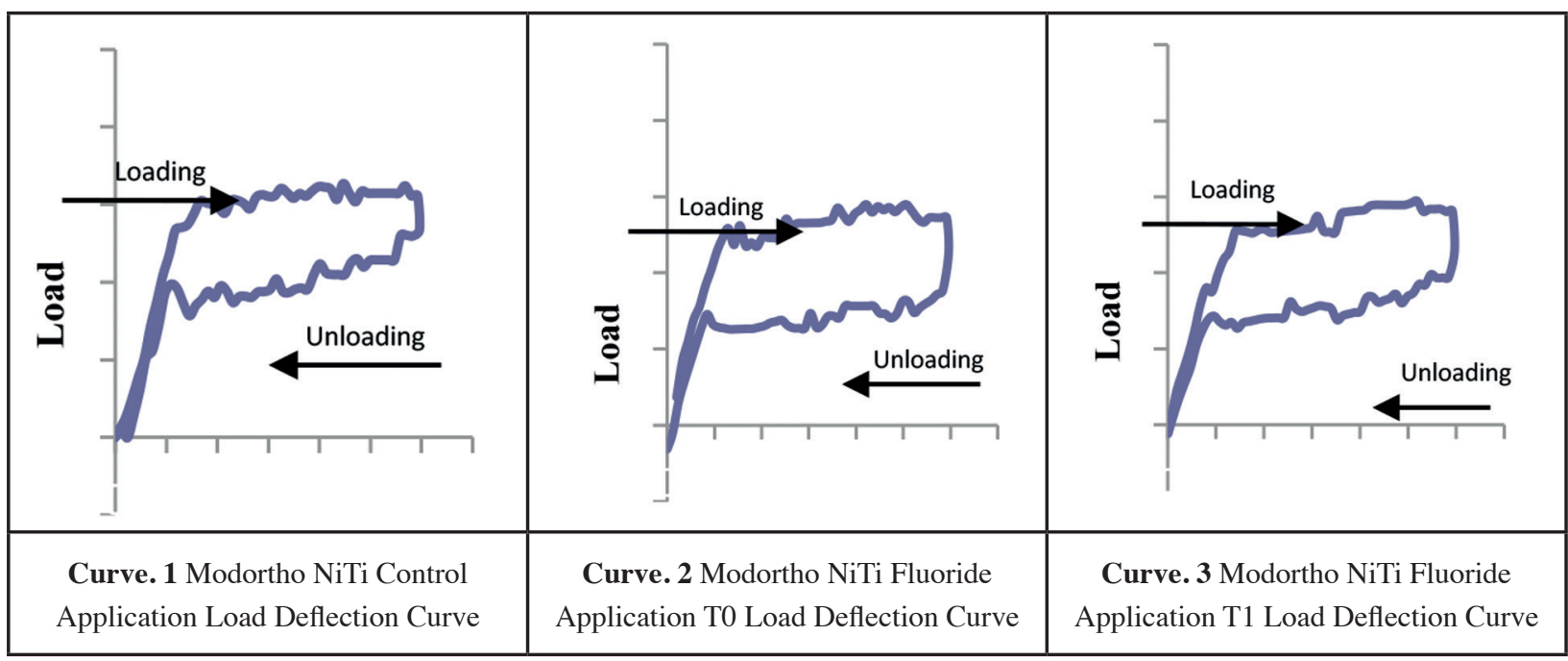




\section{Delayed mododrtho st st 17x25 1 T.M}

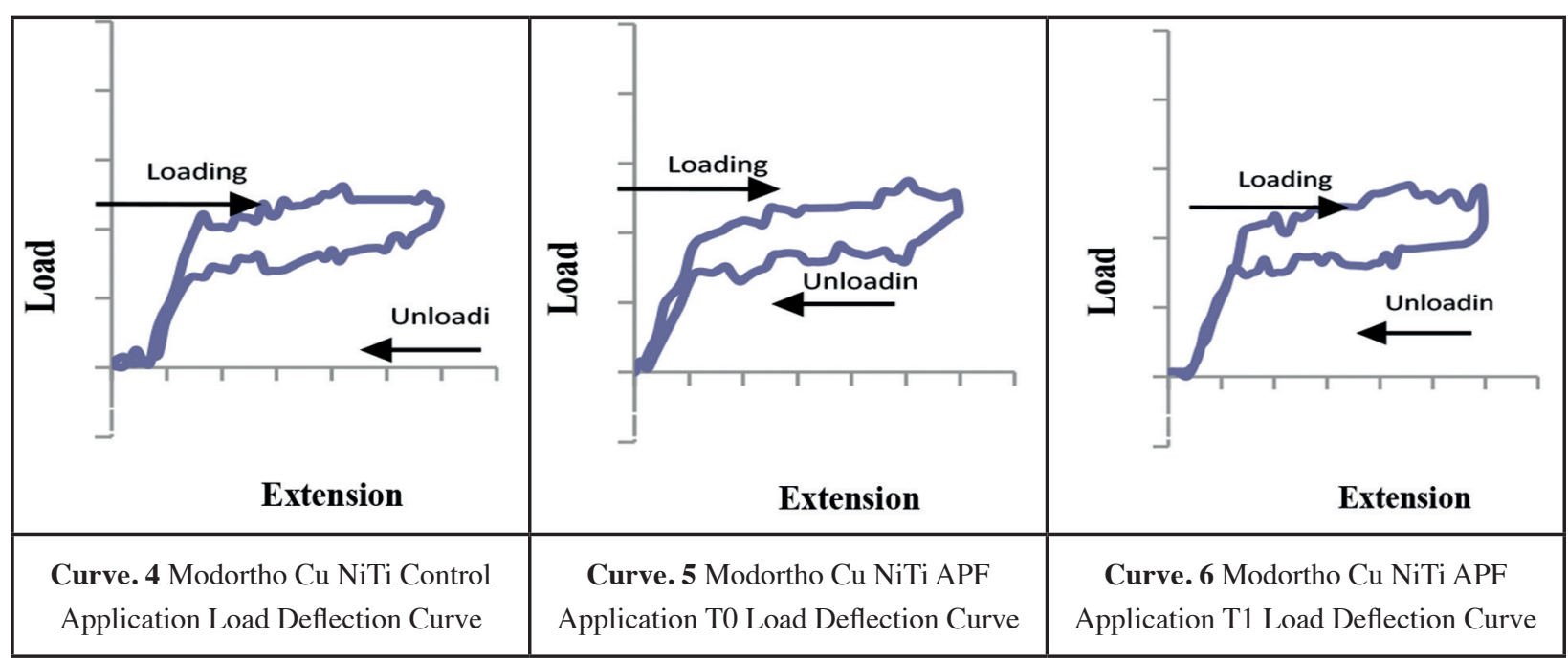

Table (3): GLM analysis showing significance of different variables on modulus of elasticity (E) of NiTi wires

\begin{tabular}{|c|c|c|c|c|c|c|}
\hline & Source & Type III Sum of Squares & df & Mean Square & F & Sig. \\
\cline { 2 - 7 } & Corrected Model & $43533.192^{\mathrm{a}}$ & 27 & 1612.340 & 24.132 & .000 \\
\cline { 2 - 7 } & Intercept & 1573819.301 & 1 & 1573819.301 & 23555.686 & .000 \\
\hline \multirow{4}{*}{ Main effect } & Treat & 948.850 & 3 & 316.283 & 4.734 & .003 \\
\cline { 2 - 7 } & Dim & 31786.761 & 1 & 31786.761 & 475.759 & .000 \\
\cline { 2 - 7 } & Time & 425.580 & 1 & 425.580 & 6.370 & .012 \\
\hline \multirow{3}{*}{$\begin{array}{c}\text { Two way } \\
\text { interaction }\end{array}$} & treat* dim & 3508.815 & 3 & 1169.605 & 17.506 & .000 \\
\cline { 2 - 7 } & treat * time & 655.968 & 2 & 327.984 & 4.909 & .008 \\
\cline { 2 - 7 } & dim * time & 62.234 & 1 & 62.234 & .931 & .335 \\
\hline
\end{tabular}

Significance level $P \leq 0.05$

TABLE (4): Descriptive statistics showing effect of Time on Modulus of elasticity (E) of NiTi wires.

\begin{tabular}{|c|c|c|c|c|}
\hline \multirow{2}{*}{ Time } & Mean & \multirow{2}{*}{ Std. Error } & \multicolumn{2}{|c|}{$95 \%$ Confidence Interval } \\
\cline { 3 - 5 } & & & Lower Bound & Upper Bound \\
\hline T0 & 77.938 & .653 & 76.652 & 79.224 \\
T1 & $74.057^{\mathrm{a}}$ & .738 & 72.604 & 75.510 \\
\hline
\end{tabular}


TABLE (5): GLM analysis showing significance of different variables on modulus of elasticity (E) of $\mathrm{Cu}$ NiTi wires

\begin{tabular}{|c|c|c|c|c|c|c|}
\hline & Source & $\begin{array}{c}\text { Type III Sum of } \\
\text { Squares }\end{array}$ & Df & Mean Square & $\mathrm{F}$ & Sig. \\
\hline & $\begin{array}{c}\text { Corrected } \\
\text { Model }\end{array}$ & $50833.005^{\mathrm{a}}$ & 14 & 3630.929 & 35.480 & .000 \\
\hline & Intercept & 814565.690 & 1 & 814565.690 & 7959.607 & .000 \\
\hline \multirow{3}{*}{ Main effect } & Treat & 1500.952 & 3 & 500.317 & 4.889 & .003 \\
\hline & Dim & 39630.860 & 1 & 39630.860 & 387.257 & .000 \\
\hline & Time & 4308.285 & 1 & 4308.285 & 42.099 & .000 \\
\hline \multirow{6}{*}{$\begin{array}{l}\text { Two way } \\
\text { interaction }\end{array}$} & treat $* \operatorname{dim}$ & 903.384 & 3 & 301.128 & 2.943 & .035 \\
\hline & treat $*$ time & 1268.045 & 3 & 422.682 & 4.130 & .008 \\
\hline & $\operatorname{dim} *$ time & 1047.252 & 1 & 1047.252 & 10.233 & .002 \\
\hline & Error & 13815.553 & 135 & 102.337 & & \\
\hline & Total & 945686.670 & 150 & & & \\
\hline & Corrected Total & 64648.558 & 149 & & & \\
\hline
\end{tabular}

Significance level $P \leq 0.05$

TABLE (6): Descriptive statistics showing effect of Time on Modulus of elasticity of Cu NiTi wires

\begin{tabular}{|c|c|c|c|c|}
\hline \multirow{2}{*}{ Time } & \multirow{2}{*}{ Mean } & \multirow{2}{*}{ Std. Error } & \multicolumn{2}{|c|}{$95 \%$ Confidence Interval } \\
\cline { 4 - 5 } & & & Lower Bound & Upper Bound \\
\hline T0 & 80.830 & 1.131 & 78.593 & 83.067 \\
T1 & $71.850^{\mathrm{a}}$ & 1.209 & 69.459 & 74.241 \\
\hline
\end{tabular}

TABLE (7) Multiple comparison for wire dimensions

Pairwise Comparisons

Dependent Variable:E

\begin{tabular}{|c|c|c|c|c|c|c|}
\hline \multirow[b]{2}{*}{ (I) $\operatorname{dim}$} & \multirow[b]{2}{*}{ (J) dim } & \multirow{2}{*}{$\begin{array}{c}\text { Mean Difference } \\
\text { (I-J) }\end{array}$} & \multirow[b]{2}{*}{ Std. Error } & \multirow[b]{2}{*}{ Sig. ${ }^{b}$} & \multicolumn{2}{|c|}{$\begin{array}{l}\text { 95\% Confidence Interval for } \\
\text { Difference }^{\mathrm{b}}\end{array}$} \\
\hline & & & & & Lower Bound & Upper Bound \\
\hline 1.00 & 2.00 & $32.709^{*}$,a & 1.656 & .000 & 29.435 & 35.984 \\
\hline 2.00 & 1.00 & $-32.709-{ }^{*}, \mathrm{c}$ & 1.656 & .000 & $-35.984-$ & $-29.435-$ \\
\hline
\end{tabular}




\section{DISCUSSION}

Compromised oral hygiene is a frequent complication with orthodontic fixed appliance therapy and can lead to enamel demineralization with the formation of white spot lesions and/ or decay, despite the presence of fluorides in the environment in toothpastes and mouth rinses. To address this potential treatment complication, orthodontists commonly prescribe a daily topical fluoride rinse and at the same time encourage in- office professional application of fluoride prophylactic agents. ${ }^{6,7}$

The effects of such fluoridated prophylactic agents have been investigated, especially on titanium based alloys mainly from the view point of surface changes and discoloration ${ }^{5}$. There is limited information regarding the effect of prophylactic fluoride agents on the mechanical properties of wire alloys used today. For this reason, this in vitro study was conducted to evaluate the effect of two widely used prophylactic agents on mechanical properties of, nickel titanium, and copper nickel-titanium wires.

The APF (Acidulated phosphate fluoride) was chosen since it represents one of the most commonly used high concentration professionally applied fluorides ${ }^{17,18}$. While MI Paste, which contains casein phosphoprotien amorphous calcium phosphate (CPP ACP) was used to represent a valid alternative to the conventional used fluorides.

This study also included a round cross-sectional wire group as well as a rectangular one. The reason that this selection was made can be attributed to the following; there is a difference in the manufacturing process of both round and rectangular wires ${ }^{19}$. These differences could have a significant effect on all the physical and mechanical properties of these wires. Furthermore different cross-sections have different surface area to volume ratios ${ }^{20,21,22}$. This dissimilarity could have an effect on the way that the wire interacts with external environmental influences. These influences include the effect of the prophylactic agents studied.

Topical application of fluoride especially in acidulated form has been reported to cause corrosion and deterioration of several properties of titanium based superelastic wires ${ }^{5,6,10}$.These changes can be explained by the phenomena of hydrogen absorption and embrittlement that was previously documented for titanium based wires ${ }^{17}$.Hydrogen absorption and embrittlement of titanium-based alloys after fluoride exposure could be clarified by the fact that, although the surface oxide of titanium is known to be highly effective in reducing hydrogen penetration,ionizable fluoride compounds, such as sodium fluoride and hydrogen fluoride, activate the surface and can cause rapid corrosion. When titanium-based orthodontic wires are exposed to acidulated topical fluoride agents, it is suggested that hydrofluoric acid (HF) is produced according to the following equation (1) and dissolves the protective oxide layer on the surface of titanium and its alloys according to equations 2-45.

$$
\begin{aligned}
& \mathrm{H} 3 \mathrm{PO} 4+3 \mathrm{NaF} \rightarrow \mathrm{Na} 3 \mathrm{PO} 4+3 \mathrm{HF}(1) \\
& \mathrm{Ti} 2 \mathrm{O} 3+6 \mathrm{HF} \rightarrow 2 \mathrm{TiF} 3+3 \mathrm{H} 2 \mathrm{O}(2) \\
& \mathrm{TiO} 2+4 \mathrm{HF} \rightarrow \mathrm{TiF} 4+2 \mathrm{H} 2 \mathrm{O}(3) \\
& \mathrm{TiO} 2+2 \mathrm{HF} \rightarrow \mathrm{TiOF} 2+\mathrm{H} 2 \mathrm{O}(4)
\end{aligned}
$$

It was stated previously that the copper component of the $\mathrm{Cu} \mathrm{NiTi}$ wires appear to inhibit fluoride related degradation of the mechanical properties of those wires. However, he also stated that the copper component did not appear to be as effective in inhibiting surface pitting and corrosion. This finding is partial supported in this study with our finding that the $\mathrm{E}$ values for $\mathrm{Cu}$ NiTi wires showing a less substantial change.

Regarding the results for the NiTi testing, GLM main analysis interaction showed a significant effect for all tested independent variables on the measured 
E values. Multiple Comparisons Tests showed the two prophylactics caused a statistically significant reduction in the measured $\mathrm{E}$ values. Whist the comparison between the prophylactic agents showed no statistically significant difference between them.

Storage time had a statistically significant effect on the measured $\mathrm{E}$ values. The values of $\mathrm{E}$ measured at $\mathrm{T} 1$ were significantly less than those measured in $\mathrm{T} 0$.

As regards to $\mathrm{Cu}$ NiTi testing GLM analysis demonstrated significant effect for all the tested independent variables. The Multiple Comparison Tests exhibited a statistically significant reduction of the measured $\mathrm{E}$ values for both prophylactic agents compared to the control. The APF prophylactic agent showed statistically lower E values when compared with MI Paste.

In terms of time the $\mathrm{E}$ values measured at $\mathrm{T} 1$ were significantly lower than those measured at $\mathrm{T} 0$.

\section{CONCLUSIONS}

It could be concluded that NiTi wires are highly susceptible to dental prophylactic agents especially acidulated fluorides. The reduction in the values of the modulus of elasticity indicates the deterioration of the mechanical properties of the NiTi wires. Whereas, $\mathrm{Cu} \mathrm{NiTi}$ wires were more resistant to the influence of the tested prophylactic agents

\section{REFERENCES}

1. Kapila S and Sachdeva R. Mechanical Properties and Clinical Applications of Orthodontic Wires.Am J Orthod Dentofacial Orthop 1989; 96: 100-9.

2. Kusy RP: A review of contemporary archwires: Their properties and characteristics. Angle Orthod 1997; 67(3): 197-08.

3. Margherita Santoro, Olivier F. Nicolay, and Thomas J. Cangialosi. Pseudoelasticity and thermoelasticity of nickeltitanium alloys: A clinically oriented review. Part I: Temperature transitional ranges. Am J Orthod Dentofacial Orthop 2001;119:587-93.
4. Margherita Santoro, Olivier F. Nicolay, and Thomas J. Cangialosi. Pseudoelasticity and thermoelasticity of nickeltitanium alloys: A clinically oriented review. Part II: Temperature transitional ranges. Am J Orthod Dentofacial Orthop. 2001;119:594-603

5. Walker MP, White RJ and Kula KS. Effect of fluoride prophylactic agents on the mechanical properties of nickel-titanium-based orthodontic wires. Am J Orthod Dentofacial Orthop 2005; 127: 662-669.

6. Huang H. Variation in surface topography of different NiTi orthodontic archwires in various commercial fluoride-containing environments.Dental Materials 2007; 23: 24-33.

7. Ogaard B, Rolla G and Arends J. Orthodontic appliances and enamel demineralization. Part 1. Lesion development. Am J Orthod Dentofacial Orthop. 1988; 94: 68-73.

8. Ogaard B. Prevalence of white spot lesions in 19-year olds: A study on untreated and orthodontically treated persons 5 years after treatment. Am Journal of Orthod Dentofacial Orthop. 1989; 96:423-427.

9. Ogaard B. White spot lesions during orthodontic treatment: mechanisms and fluoride preventive aspects. Semin Orthod. 2008; 14: 183-193.

10. Chadwick BL, Roy J, Knox J, Treasure ET. The effect of topical fluorides on decalcification in patients with fixed orthodontic appliances: A Systematic Review. Am J Orthod Dentofacial Orthop. 2005; 128: 601-606.

11. Behnan A. O., Arruda A. O., González-Cabezas C., Sohn W. and Peters M. C. In-vitro evaluation of various treatments to prevent demineralization next to orthodontic brackets. Am J Orthod Dentofacial Orthop. 2010; 138: 712.e1-e7.

12. Michael A. Robertson, Chung How Kau, Jeryl D. English, Robert P. Lee, John Powers, and Jennifer T. Nguyenf. MI Paste Plus to prevent demineralization in orthodontic patients: A prospective randomized controlled trial. Am J Orthod Dentofacial Orthop. 2011; 140 (5): 660-668.

13. Segner D and Ibe D: Properties of superelastic wires and their relevance to orthodontic treatment. Eur J Orthod. 1995; 17:395-402.

14. Reitan K. Some Factors Determining The Evaluation of Forces in Orthodontics, Am J Orthod, 1957; 43(1): 32-45.

15. Quinn R S and Yoshikawa D K. A Reassessment of Force Magnitude in Orthodontics. Am J Orthod. 1985; 88(3): 252-260. 
16. Watanabe I and Watanabe E. Surface Changes Induced by Fluoride Prophylactic Agents on Titanium-Based Orthodontic Wires. Am J Orthod Dentofacial Orthop. 2003; 123: 653-656.

17. Yokoyama K, Kaneko K, Moriyama K, Asaoka K, Sakai J, Nagumo M. Hydrogen embrittlement of Ni-Ti superelastic alloy in fluoride solution. J Biomed Mater Res 2003;65:182-7.

18. Walker MP, Ries D, Kula K, Ellis M and Fricke B. Mechanical Properties and Surface Characterization of Beta Titanium and Stainless Steel Orthodontic Wire Following Topical Fluoride Treatment. Angle Orthodontist 2007; 77: 342:348.

19. Gurgel Jde A, Kerr S, Powers JM and LeCrone V. ForceDeflection Properties of Superelastic Nickel-Titanium
Archwires, Am J Orthod Dentofacial Orthop. 2001;120 (4): $378-382$

20. Kohl RW: Metallurgy In Orthodontics. Am J Orthod; 1981;34: 37-52.

21. Wilkinson PD, Dysart PS, Hood JAA, and Herbison GP. Load-deflection characteristics of superelastic nickel-titanium orthodontic wires. Am J Orthod Dentofacial Orthop 2002;121:483-495.

22. Asgharnia MK and Brantley WA. Comparison of bending and tension tests for orthodontic wires. Am J Orthod. 1986;89:228-236.

23. Miura F, Mogi M, Ohura Y, Hamanaka H. The super-elastic property of Japanese NiTi alloy wire for use in orthodontics. Am J Orthod Dentofacial Orthop 1986; 90:1-10 